\title{
Potentiometric Sensors for the Determination of Valdecoxib in Pharmaceutical Preparation
}

\author{
Salwa Fares Rassi \\ Department of Chemistry, Faculty of Sciences, University of Al- Baath Homs, Syria. Mobile: 00963- \\ 966-243153* \\ E-mail address: salwarassi @ gmail.com
}

Keywords: Valdecoxib, selective electrode, 5,6-diamino-2-thiouracil hydrochloride.

\begin{abstract}
Valdecoxib (VALD) selective electrodes based on VALD-5,6-diamino-2-thiouracil hydrochloride (DTUH) (VALD-DTUH) ion pair in PVC matrix membrane were constructed. The plasticizers used were dibutylphthalate (DBP) (Electrode B) tri-n-butylphosphate (TBP) (electrode C), or dioctylphthalate (DOP) (electrode) A. The electrodes gave the linear range between $6.0 \times 10^{-6}$ $17.9 \times 10^{-3}, 2.5 \times 10^{-5}-8.3 \times 10^{-3} \mathrm{M}, \mathrm{M}$ and $2.5 \times 10^{-6}-2.0 \times 10^{-2} \mathrm{M}$ respectively. The slopes for linear range ranged from 39.29 to $58.76 \mathrm{mV} /$ decade with correlation coefficients lying between 0.997 , 0.989 and 0.999 respectively. The best detection limit was $1.50 \times 10^{-6} \mathrm{M}$ for the electrode based on DOP. Selectivity coefficients of VALD related to a number of interfering cation and some organic compounds and excipients were studied using matched potential method (MPM(, and there were negligible interference caused by most of the investigated species. The $\mathrm{pH}$ and life time of the electrodes were also studied. The direct determination of VALD shows an average recovery of (100.08-100.61 and 99.75-101.00)\% and a mean relative standard deviation of (2.70-0.61 and 2.39$0.56) \%$ for sensor A and B respectively. The results obtained by determination of VALD in tablets using the proposed sensors which comparable favorably with those obtained by spectrophotometric method. Validation of the method shows the suitability of the electrodes for the determination of VALD in pharmaceutical formulation.
\end{abstract}

\section{INTRODUCTION}

The determination of bulk drugs has become increasingly important in the pharmaceutical industry. Ion selective membranes have been widely used for drug analysis with the advantage of determining the sample directly, rapidly, and more easily. Valdecoxib (VALD) is a new antiinflammatory drug that is highly selective for inhibition of the inducible form of cyclooxygenase (COX-2) [1]. This drug (Bextra, Pharmacia) has recently been approved by the US-FDA for treatments of rheumatoid arthritis, osteoarthritis and pain

[2-6]. VALD chemically is 4-(5-methyl-3-phenyl-4-oxazolyl)benzenesulfonamide, and its chemical structures is shown in (Figure 1). VALD is metabolized primarily by cytochrome P450 2C9 and $3 \mathrm{~A} 4$ to the pharmacological active hydroxylated metabolite and the carboxylic acid metabolite in humans [7-9].

Different methods have been used for the determination of VALD in products and biological samples such as high-performance liquid chromatography (HPLC) [10-23], and spectrophotometry [24-29]. No potentiometric methods have yet been reported for the determination of VALD.

In the present work, a plastic membrane electrode selective for the VALD cation was constructed and its performance characteristics were studied. In this work, three VALD electrodes were constructed with different plasticizers based on 5,6-diamino-2-thiouracil hydrochloride DTUH as novel ionophore. The electrodes are based on the incorporation of $\mathrm{VALD}^{+} \mathrm{DTUH}^{-}$ion pair complex in a polyvinyl chloride (PVC) membrane plasticized with

(DOP, DBP, TBP). The electrodes have been successfully used as a sensor to determination VALD in pure solutions and the pharmaceutical. The properties of the prepared electrodes, $\mathrm{pH}$ effect, and selectivity coefficient measurements were evaluated. 


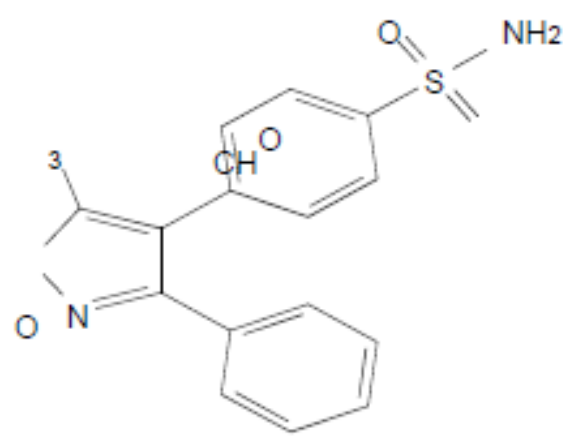

Figure 1. Chemical structure valdecoxib (VALD).

\section{EXPERIMENTAL}

\subsection{Apparatus}

Potentiometric and $\mathrm{pH}$ measurements were carried out using a digital Schott Geräte pHmeter, were made with Consort C 830 (Belgium) with combined glass $\mathrm{pH}$ electrode. A water bath shaker (Grant instruments, Cambridge Ltd., England) was used to control the temperature of the test solutions. A saturated calomel electrode (SEC) was used as the external reference (Mettler, Switzerland), while an $\mathrm{Ag} / \mathrm{AgCl}$ electrode was prepared electrically and used as an internal reference electrode. The electrochemical system may be represented as follows:

$\mathrm{Ag} / \mathrm{AgCl} \mid$ inner solution|membrane|test solution $\| \mathrm{KCl}$ salt bridge $\| \mathrm{Hg} / \mathrm{HgCl}_{2}$ (sat.) (NMR Spectrometry Bruker ,400MHz), FT/IR 4100(Fourier transform infrared spectrometer) Jasco.

\subsection{Reagents and materials}

All of the chemicals used were of analytical grade. Doubly distilled water was used to prepare all solution. High molecular weight poly (vinyl chloride) (PVC) was from SABIC Co., dioctylphthalate 98.9\% (DOP), tri-n-butylphosphate 97\% (TBP), and di-n-butylphthalate 99\% (DBP) were obtained from BDH Co., England, while tetrahydrofuran (THF) was obtained from Medex, England. Pure-grade VALD $\left(\mathrm{C}_{16} \mathrm{H}_{14} \mathrm{~N}_{2} \mathrm{O}_{3} \mathrm{~S}, 314.36 \mathrm{~g} \cdot \mathrm{mol}^{-1}\right)$ was supplied by Aarti Drugs Limited (Indian). Its purity was found to be $99.32 \%$ according to the compendia method. Uracil5,6-diamino-2-thio hydrochloride (DTUH) (C4H7N4OSCl, 194.5 g.mole ${ }^{-1}$ ) was synthesized (Fig. 1) and identified in laboratory by spectroscopic means. The H-NMR and IR data (Fig. 2.) of DTUH shown in (Table 1). shown in (Table 1). VALD tablets supplied by Pharmasyr (Damascus, Syria), each tablet was labeled to contain VALD $10,20 \mathrm{mg} / \mathrm{tab}$. A stock solution of $0.01 \mathrm{M}$ VALD was prepared by dissolving an appropriate amount $(0.314 \mathrm{~g})$ of the compound in $25 \mathrm{ml}$ methanol and making the solution up to $100 \mathrm{~mL}$ with water. A standard VALD solution $\left(1.0 \times 10^{-2}-1.0 \times 10^{-6} \mathrm{M}\right)$ were prepared daily by sequential dilution of the appropriate stock solutions with the background solution. The solution of $0.01 \mathrm{M}$ DTUH was prepared by dissolving appropriate amount of the compound in the methanol. VALD and DTUH stock solutions were stored in dark at refrigerator. Stock solutions of $0.1 \mathrm{M}$ for each of $\mathrm{LiCl}, \mathrm{NaCl}, \mathrm{KCl}, \mathrm{NH}_{4} \mathrm{Cl}, \mathrm{CaCl}_{2}, \mathrm{MgCl}_{2}, \mathrm{BaCl}_{2}, \mathrm{ZnCl}_{2}, \mathrm{MnSO}_{4}$, $\mathrm{Ni}\left(\mathrm{NO}_{3}\right)_{2}, \mathrm{Co}\left(\mathrm{NO}_{3}\right)_{2}, \mathrm{Cu}\left(\mathrm{NO}_{3}\right)_{2}, \mathrm{~Pb}\left(\mathrm{NO}_{3}\right)_{2}, \mathrm{FeCl}_{3}, \mathrm{AlCl}_{3}, \mathrm{CrCl}_{3}$, glucose, fructose, lactose, starch, micro crystalline cellulose, carboxymethyl cellulose, polyethylene glycol, titanium dioxide, and polysorbate 80 were prepared by dissolving the appropriate amount of the compounds. More diluted solutions were prepared by subsequent dilutions of the stock solutions.

\subsection{Procedure for pharmaceutical formulations.}

The homogenized powder was prepared from 10 accurately weighed VALD tablets. An appropriate amount of this powder was dissolved in methanol and doubly distilled water. Dissolution of the drug was assisted by means of a magnetic stirrer and by an ultrasonic bath. The mixture was then 
filtered and mad up to the mark in a $100-\mathrm{mL}$ volumetric flask. Different volumes of the stock solution were taken and subjected to the direct and standard addition methods

\subsection{Procedure for Preparation of ion-pair compounds}

Ion-pair $\left(\mathrm{VALD}^{+} \mathrm{DTUH}^{-}\right)$was prepared by mixing equal volumes of $10^{-2} \mathrm{M}$ methanolic solutions of VALD and DTUH under stirring. The precipitate resulted after the evaporation methanol. The obtained precipitate was filtered, washed thoroughly with distilled water to remove any non-complex material, dried at room temperature and ground to a fine powder in a mortar. $1 \mathrm{H}-$ NMR and IR data (Figure 2). of VALD ${ }^{+}$DTUH $^{-}$shown in (Table 1).

Table 1. H-NMR and IR data for DTUH and Complex between DTUH and VALD

\begin{tabular}{|c|c|c|c|c|c|}
\hline \multicolumn{3}{|c|}{ H-NMR/ $\delta$ ppm } & \multicolumn{3}{|c|}{$\mathrm{IR} / \mathrm{cm}^{-1}$} \\
\hline & VALD $^{+}$DATUH $^{-}$ & DATUH & & DATUH & VALD $^{+}$DATUH \\
\hline$-\mathrm{SH}$ & -- & 12.48 & $-\mathrm{SH}$ & 2479 & --- \\
\hline$-\mathrm{OH}$ & 11.57 & 11.55 & $-\mathrm{OH}$ & 3460 & 3460 \\
\hline$-\mathrm{NH}_{3}^{+}$ & 8.17 & 6.27 & $-\mathrm{NH}_{2}$ & $3328-3390$ & $3325-3375$ \\
\hline$-\mathrm{NH}_{3}^{+}$ & 7.09 & 8.00 & $\mathrm{~N}-\mathrm{S}$ & ---- & 1186 \\
\hline \multirow[t]{2}{*}{$\mathrm{CH}_{3}$} & 2.84 & & $\mathrm{~N}-\mathrm{O}$ & & 1336 \\
\hline & & & $\mathrm{C}=\mathrm{C}$ & & 1621 \\
\hline 9 H Aromatic & $7.79-7.41$ & & $\mathrm{C}=\mathrm{N}$ & & 1550 \\
\hline
\end{tabular}

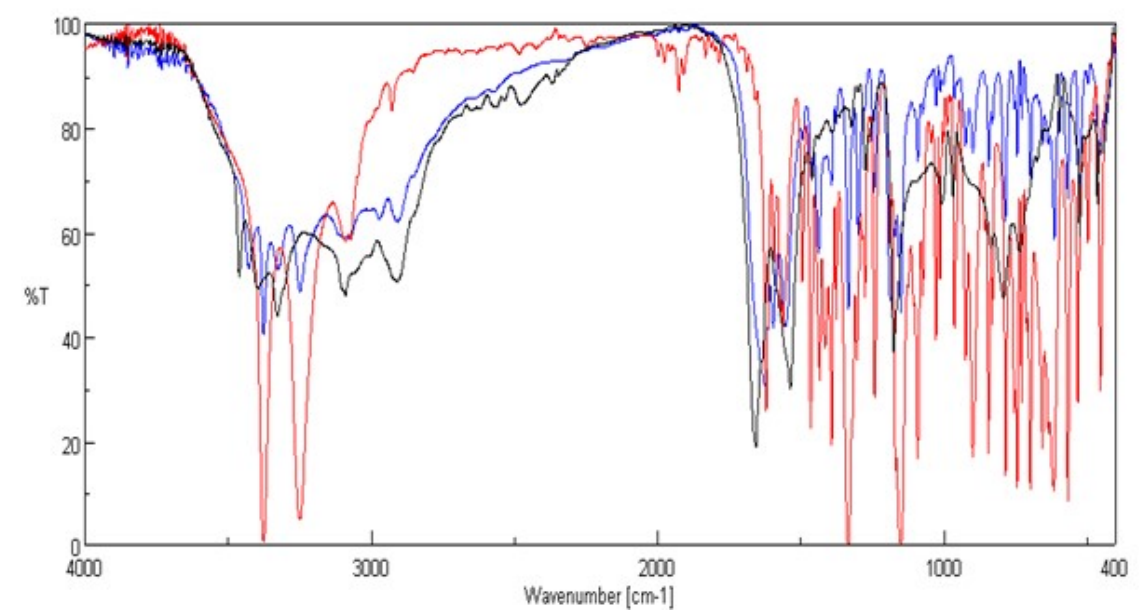

Figure 2. IR spectrum of DTUH (black spectrum), VALD (red spectrum), and VALD +DTUH Complex (blue spectrum)

So, the composition of the ion pair complex was confirmed by NMR and IR spectrophotometry to be 1:1 (VALD: DTUH). The ionic pond is set up between sulfoamine group at VALD cation and thio group at DTUH anion.

\subsection{Construction of valdecoxib membrane electrodes}

The electrodes were constructed according to the method of Craggs et al. [30]. The membrane composition was studied by varying the percentages $(\mathrm{w} / \mathrm{w})$ of the ion pair complex, PVC and DOP (electrode A), DBP (electrode B), or TBP (electrode C) as plasticizing solvent mediators. The optimum composition that exhibits the perfect performance characteristics is reached. The 
membranes were prepared by dissolving the required amount of ion pair complex, PVC and DOP, DBP or TPP in THF. The homogeneous mixture were poured into glass Petri dishes $(8 \mathrm{~cm}$ diameter), and was then covered with a glass plate, and allowed to evaporate overnight at room temperature. The thickness of obtained membrane was about $0.15 \mathrm{~mm}$. Membranes $(12 \mathrm{~mm}$ diameter) were cut out and glued using PVC-THF paste to the polished end of a plastic cap attached to a glass tube. The electrodes bodies was filled with a solution of $1 \times 10^{-1} \mathrm{M} \mathrm{KCl}$ and $1 \times 10^{-3} \mathrm{M}$ VALD was used as the inner electrolyte, and $\mathrm{Ag} / \mathrm{AgCl}$ was dip in it as internal reference electrode. The electrode potential was measured against the SCE as the reference electrode. Initially, the membrane electrodes were conditioned by soaking into $1 \times 10^{-3} \mathrm{M}$ of VALD solution for $2 \mathrm{~h}$. When offuse, the electrodes were stored in air.

\subsection{Selectivity of sensors}

The potentiometric selectivity coefficient $\mathrm{K}_{\mathrm{A}, \mathrm{B}}^{\mathrm{MPM}}$ of an ISE commonly used as quantitative expression of the ability of the electrode to respond primarily to the analyte ion in the presence of interfering ions. The influence of the presence of some different species on the response of VALD sensors was investigated. The selectivity coefficient $\mathrm{K}^{\mathrm{pot}} \mathrm{A}, \mathrm{B}$ of the proposed sensors were calculated in the presence of related organic and inorganic substances using matched potential method (MPM) $[31,32]$

The selectivity coefficient $\mathrm{K}_{\mathrm{A}, \mathrm{B}}^{\mathrm{pot}}$ measured by Matched Potential method was calculated from the following equation

$$
\mathrm{K}^{\mathrm{MPM}}{ }_{\mathrm{A}, \mathrm{B}}=\left(\mathrm{a}_{\mathrm{A}}{ }_{\mathrm{A}}-\mathrm{a}_{\mathrm{A}}\right) / \mathrm{a}_{\mathrm{B}}
$$

Where $\mathrm{a}_{\mathrm{A}}$ known activity of primary ion, $\mathrm{a}_{\mathrm{A}}$ fixed activity of primary ion and $\mathrm{a}_{\mathrm{B}}$ activity of interfering ions.

Table 1. Optimization of the membrane ingredients

\begin{tabular}{|c|c|c|c|c|c|}
\hline \multicolumn{4}{|l|}{ composition, $\%(\mathrm{w} / \mathrm{w})$} & slope & Detection limit \\
\hline Membrane & ion pair complex & PVC & DOP & $\mathrm{mV}$. decade $^{-1}$ & $\mathrm{M}$ \\
\hline 1 & 2 & 49.0 & 49.00 & 45.44 & $4.02 \times 10^{-5}$ \\
\hline 2 & 4 & 48.0 & 48.00 & 48.57 & $5.72 \times 10^{-5}$ \\
\hline 3 & 6 & 47.0 & 47.00 & 50.88 & $7.20 \times 10^{-5}$ \\
\hline 4 & 8 & 46.0 & 46.00 & 54.98 & $9.50 \times 10^{-5}$ \\
\hline 5 & 9 & 45.5 & 45.54 & 56.03 & $1.83 \times 10^{-6}$ \\
\hline $\mathbf{6}$ & $\mathbf{1 0}$ & $\mathbf{4 5 . 0}$ & $\mathbf{4 5 . 0 0}$ & $\mathbf{5 8 . 7 6}$ & $\mathbf{1 . 5 0 \times 1 0 ^ { - 6 }}$ \\
\hline 7 & 11 & 44.5 & 44.50 & 55.29 & $9.10 \times 10^{-5}$ \\
\hline 8 & 12 & 44.0 & 44.00 & 48.15 & $8.40 \times 10^{-5}$ \\
\hline 9 & 14 & 43.0 & 43.00 & 44.67 & $6.10 \times 10^{-5}$ \\
\hline 10 & 16 & 42.0 & 42.00 & 40.52 & $1.20 \times 10^{-4}$ \\
\hline
\end{tabular}

\subsection{General procedure}

The performance of the three electrodes obtained was investigated by measuring e.m.f. values of $1.0 \times 10^{-6}-2.5 \times 10^{-2} \mathrm{M}$ of VALD. The electrodes were calibrated by added volumes of $0.01 \mathrm{M}$ working solution of VALD successively in $50 \mathrm{ml}$ of water and methanol to generate a total 
concentration ranging from $2.0 \times 10^{-6}-2.5 \times 10^{-2} \mathrm{M}$ VALD, followed by immersing the VALDelectrode, together with a calomel reference electrode in the solution. The potential readings were recorded after stabilization, and the e.m.f was plotted as a function of the logarithm of the VALD concentration. The concentration graph was used for subsequent determinations of unknown VALD concentrations.

\subsection{E.m.f. measurements}

All e.m.f. measurements were performed at room temperature using the cell assembly: $\mathrm{Ag} / \mathrm{AgCl} \mid$ inner solution | PVC membrane | test solution $\| \mathrm{KCl}$ salt bridge $\| \mathrm{Hg} / \mathrm{HgCl}_{2}$ (sat.)

\subsection{Potentiometric determination of VALD}

VALD has been determined potentionmetrically using the investigated electrode by the direct method and by standard addition method $[33,34]$. In this method the proposed electrode (A) was immersed into a sample of $10 \mathrm{ml}$ with an unknown concentration $\left(2.5 \times 10^{-}\right.$

$6 \quad-2$

$-2.0 \times 10 \mathrm{M}$ ) of a VALD solution, and the equilibrium potential of $\mathrm{E}_{\mathrm{u}}$ was recorded. Then, $1 \mathrm{ml}$ of $0.01 \mathrm{M}$ of standard VALD was added into the testing solution and the equilibrium potential of $\mathrm{E}_{\mathrm{s}}$ was obtained. From the potential change, $\Delta \mathrm{E}=\mathrm{E}_{\mathrm{u}}-\mathrm{E}_{\mathrm{s}}$, we could determine the concentration of the testing sample using the equation:

$$
\mathrm{C}_{\mathrm{x}}=\mathrm{C}_{\mathrm{s}} \mathrm{V}_{\mathrm{s}} /\left[\left(\mathrm{V}_{\mathrm{x}}+\mathrm{V}_{\mathrm{s}}\right) \times 10^{\Delta \mathrm{E} / \mathrm{S}}-\mathrm{V}_{\mathrm{x}}\right]
$$

Where $C_{x}$ and $V_{x}$ are the concentration and the volume of an unknown sample; $C_{s}$ and $V_{s}$ are the concentration and the volume of the standard, respectively; $\mathrm{S}$ is the slope of the calibration graph $\left(\mathrm{mVdecade}^{-1}\right)$ and $\Delta \mathrm{E}$ is the change in the potential $(\mathrm{mV})$. The standard addition method was applied for the determination of VALD in commercial preparations

\section{RESULTS AND DISCUSSION}

\subsection{Composition of the electrode}

The membrane composition was studied by varying the percentages $(\mathrm{w} / \mathrm{w})$ of the ion pair complex (VALD-DTUH) and plasticizer and PVC. Until the optimum composition exhibiting the best linear responses was obtained. This composition is given in Table 1. ten membranes compositions were investigated. The results showed that the electrode made by membrane (6) with $10 \%$ VALD-DTUH ion pair complex exhibited the best performance characteristics (slope $58.76 \mathrm{mV}$ decade ${ }^{-1}$, at $25^{\circ} \mathrm{C}$; usable concentration range, $2.5 \times 10^{-6} 2.0 \times 10^{-2} \mathrm{M}$ VALD; and response time $30 \mathrm{~s}$. The other membranes exhibit slopes ranging between 40.52 and $56.03 \mathrm{mV} \mathrm{dcade}^{-1}$. In all subsequent studies, electrodes made of membrane (6) were used. For all construted electrodes, the percentage of ion pair complex ranging between 6-11\% was found to offer better slopes and correlation coefficients. The results obtained with ion-pair for the three plasticizers are summarized in Table 2. The electrodes $\mathrm{A}$ and $\mathrm{B}$ exhibit comparable linear ranges and the lowest detection limit.

Table 2. Effect of the nature of an ion pair complex and a plasticizer on characteristics of the electrodes

\begin{tabular}{|c|c|c|c|c|c|c|}
\hline Electrode & $\begin{array}{c}\text { Ion-pair } \\
\%\end{array}$ & Plasticizer & $\begin{array}{c}\text { Slope } \\
\mathrm{mV} . \mathrm{decade}^{-1}\end{array}$ & $\begin{array}{c}\text { Linear range } \\
\mathrm{M}\end{array}$ & $\begin{array}{c}\text { Correlation } \\
\text { coefficient }\end{array}$ & $\begin{array}{c}\text { Limit of } \\
\text { detection } \\
\mathrm{M}\end{array}$ \\
\hline $\mathrm{A}$ & 10 & DOP & 58.76 & $2.5 \times 10^{-6}-2.0 \times 10^{-3}$ & 0.999 & $1.50 \times 10^{-6}$ \\
\hline $\mathrm{B}$ & $\mathbf{8}$ & DBP & $\mathbf{5 6 . 9 2}$ & $\mathbf{6 . 0} \times \mathbf{1 0}^{-6}-\mathbf{1 7 . 9} \times \mathbf{1 0}^{-3}$ & 0.997 & $\mathbf{3 . 1 6} \times \mathbf{1 0}^{-6}$ \\
\hline $\mathrm{C}$ & 14 & TBP & 39.29 & $2.5 \times 10^{-5}-8.3 \times 10^{-3}$ & 0.989 & $1.50 \times 10^{-5}$ \\
\hline
\end{tabular}




\subsection{Effect of internal solution}

The proposed selective electrode was also examined at different concentrations of the inner reference solution. The concentration of the internal solution of VALD in the electrode was changed from $1.0 \times 10^{-2}$ to $1.0 \times 10^{-5} \mathrm{M}$ and the potential response of the electrode was measured. It was found that variation of the concentration of the internal solution does not cause any significant different in the potential response of the electrode. A $1.0 \times 10^{-3} \mathrm{M}$ concentration of VALD as internal solution was quite appropriate for proper functioning of the electrode.

\subsection{Effect of plasticizer type on the characteristic performance of the sensor}

VALD-DTUH was a stable water insoluble ion-pair complex though readily soluble inorganic solvents such as THF, methanol, etc. The complex was incorporated into a PVC membrane with the following plasticizers: DOP (electrode A), DBP (electrode B), and TBP (electrode C). The working characteristics for the electrodes were assessed on the basis of their calibration curves. The physical properties of these membranes were as follows: white, flexible, clear, and transparent (noncrystalline). Non-Nernstian slope was obtained for electrode based on TBP. The slope is $39.29 \mathrm{mV} /$ decade with correlation coefficient 0.989 . The linear range for electrode was $1.50 \times 10^{-5}$ $8.30 \times 10^{-3} \mathrm{M}$ with detection limits of $1.50 \times 10^{-5} \mathrm{M}$. Near Nernstian slopes were obtained for the electrodes based on DOP and DBP (electrodes A and B) gave a slope of 58.76 and $56.92 \mathrm{mV}$.decade ${ }^{-1}$ with a correlation coefficient of 0.999 and 0.997 and a linear concentration range $2.5 \times 10^{-6}-2.0 \times 10^{-3} \mathrm{M}$, and $6 \times 10^{-6}-17.9 \times 10^{-3} \mathrm{M}$ a detection limit $1.50 \times 10^{-6}$ and $3.16 \times 10^{-6} \mathrm{M}$ respectively.

The TBP which has a low viscosity $(3.11 \mathrm{cSt})$, leads to leaching of the complex from the membrane or may have a high stereo effect on methyl groups. All further studies were conducted using DOP and DBP as the plasticizers.

\subsection{Effect of soaking}

Freshly prepared electrodes must be soaked to activate the surface of the membrane to form an infinitesimally thin layer for ion-exchange process to occur [35]. This preconditioning process requires different times, depending on the diffusion and equilibration at the electrode test solution interface. A fast establishment of equilibrium is certainly a condition for a fast potential response. Thus, the performance characteristic of the VALD electrode was investigated as a function of the soaking time. For this purpose the electrode was soaked in a $1 \times 10^{-2} \mathrm{M}$ solution of VALD, DTUH and water at room temperature. It was found that continuous soaking longer than $20 \mathrm{~h}$ negatively affected the response of the electrode, due to leaching of the active ingredients (ion-pair and plasticizer) to the solution. The optimum soaking time and the optimum solution was found to be 2h. for $1 \times 10^{-2} \mathrm{M}$ solution of VALD. During this period, the sensors were washed with water after each application and kept dry in air at room temperature when not in use. The results indicate that during the $2 \mathrm{~h}$ of soaking the slope remains constant around $58.76 \mathrm{mV} \cdot \operatorname{decad}^{-1}$, at $25^{\circ} \mathrm{C} .(\mathrm{E}, \mathrm{mV}$ vs. $\mathrm{t}$, min) plots (Figure 3). were obtained after the electrode was soaked continuously in $10^{-2} \mathrm{M}$ VALD, water and DTUH for 30-500 min.

\subsection{Effect of pH}

The influence of $\mathrm{pH}$ of the test solution on the potential response of the membrane for $\left(2.0 \times 10^{-5}, 2.0 \times 10^{-4}, 2.0 \times 10^{-3}, 2.0 \times 10^{-2} \mathrm{M}\right)$ VALD solution was tested by following the potential variation in the $\mathrm{pH}$ range 1-12. The electrode response for different VALD 


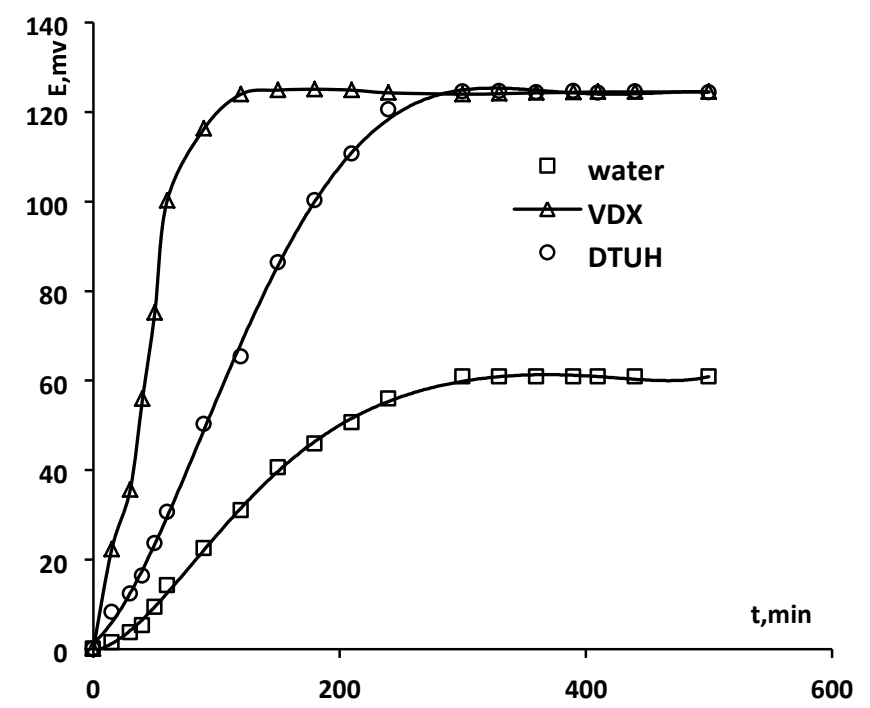

Figure 3. Effect of soak solution on response electrode

concentration was tested at various $\mathrm{pH}$ values, each time being adjusted by using hydrochloride acid or sodium hydroxide solution. Potential $\mathrm{pH}$ plots the results are given in (Figure 4). As is obvious, the membrane electrode could be suitably within the $\mathrm{pH}$ rang 1-9, the potentials remain constant did not vary by more than, $\pm 1 \mathrm{mV}$. At higher $\mathrm{pH}$ values the potential increased, the proposed electrode responds to VALD and $\mathrm{OH}^{-}$simultaneously

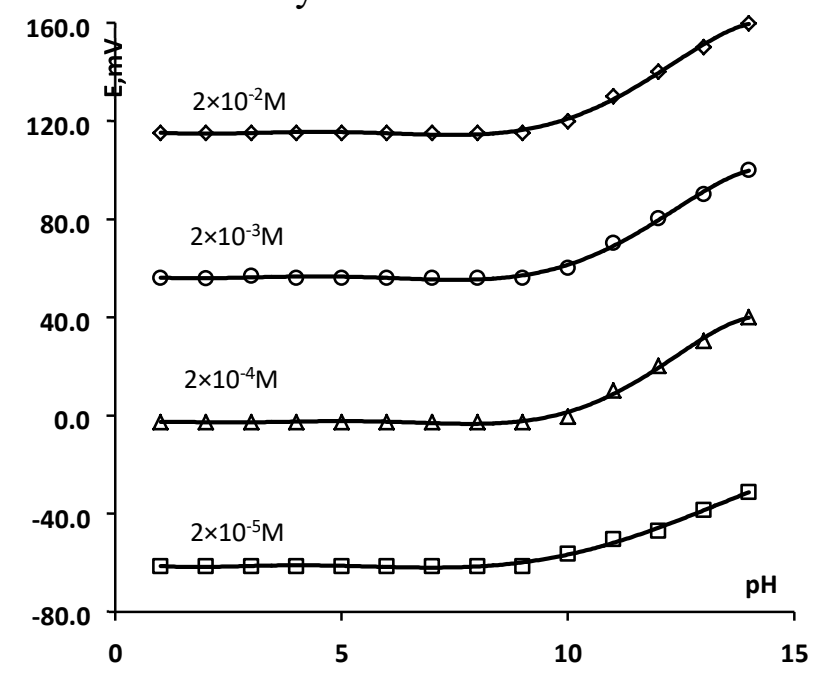

Figure.4 Effect of the $\mathrm{pH}$ on the response of the electrode

\subsection{Effect of the temperature of the test solution}

The Effect of the temperature of the test solution on the potential response of the membrane was tested by following the slopes variation in the temperature range $20-65^{\circ} \mathrm{C}$

(Figure 5). The results show that within the temperature range investigated the electrode responds practically to the VALD concentration with slopes between $58.76-57.3 \mathrm{mV} \cdot$ decad $^{-1}$ and usable concentration range of about $2.5 \times 10^{-6}-2.0 \times 10^{-3} \mathrm{M}$. 


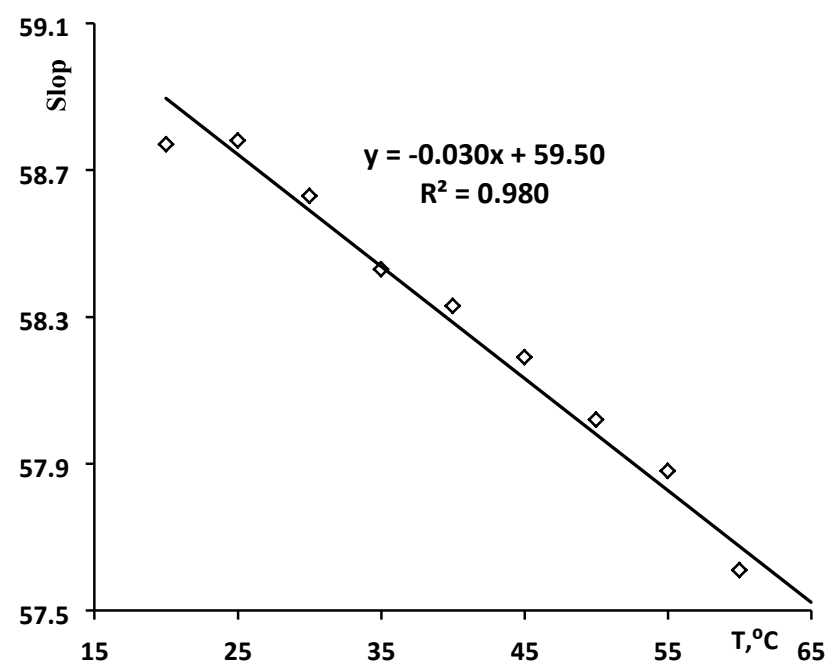

Figure 5. Effect of the temperature of the test solution on the potential response of the membrane.

\subsection{Calibration graphs}

Using the optimized membrane composition and conditions described above, the potentiometric response of the electrode was studied based on the VALD concentration in the range of $1.0 \times 10^{-6}-2.0 \times 10^{-2} \mathrm{M}$. The calibration curves for the electrodes A and B containing DOP or DBP as plasticizer gave an excellent linear response from $2.5 \times 10^{-6}-2.0 \times 10^{-3} \mathrm{M}$, as shown in (Figure 6). The results given in Table 3. show the characteristics Performance of the membrane electrodes. The least squares equation obtained from the calibration data is as follows:

$$
\mathrm{E}(\mathrm{mV})=\mathrm{S} \times \log ([\mathrm{VALD}, \mathrm{M}]+\text { intercept }
$$

where $\mathrm{E}$ is the potential and $\mathrm{S}$ the slope of the electrodes.

\subsection{Response time}

Response time is an important factor an ion-selective electrode (ISE). The time required for the electrodes to reach steady potential values, after immersion of the electrode in different concentration ranging from $2.0 \times 10^{-6}, 2.0 \times 10^{-4}$ and $2.0 \times 10^{-2} \mathrm{M}$ of VALD solution was studied. The average time was found to be short, ranging from 10- 20s for concentration $2 \times 10^{-}{ }_{2-4-6} \mathrm{M}$ and $2.0 \times 10$ $\mathrm{M}$ solution. The longer response time reached around $35 \mathrm{~s}$ at $2.0 \times 10 \mathrm{M}$. These values indicated the high stability of the electrodes during the measurements. A typical plot for response time is shown in (Figure 7) for the electrode based on DOP as the plasticizer.

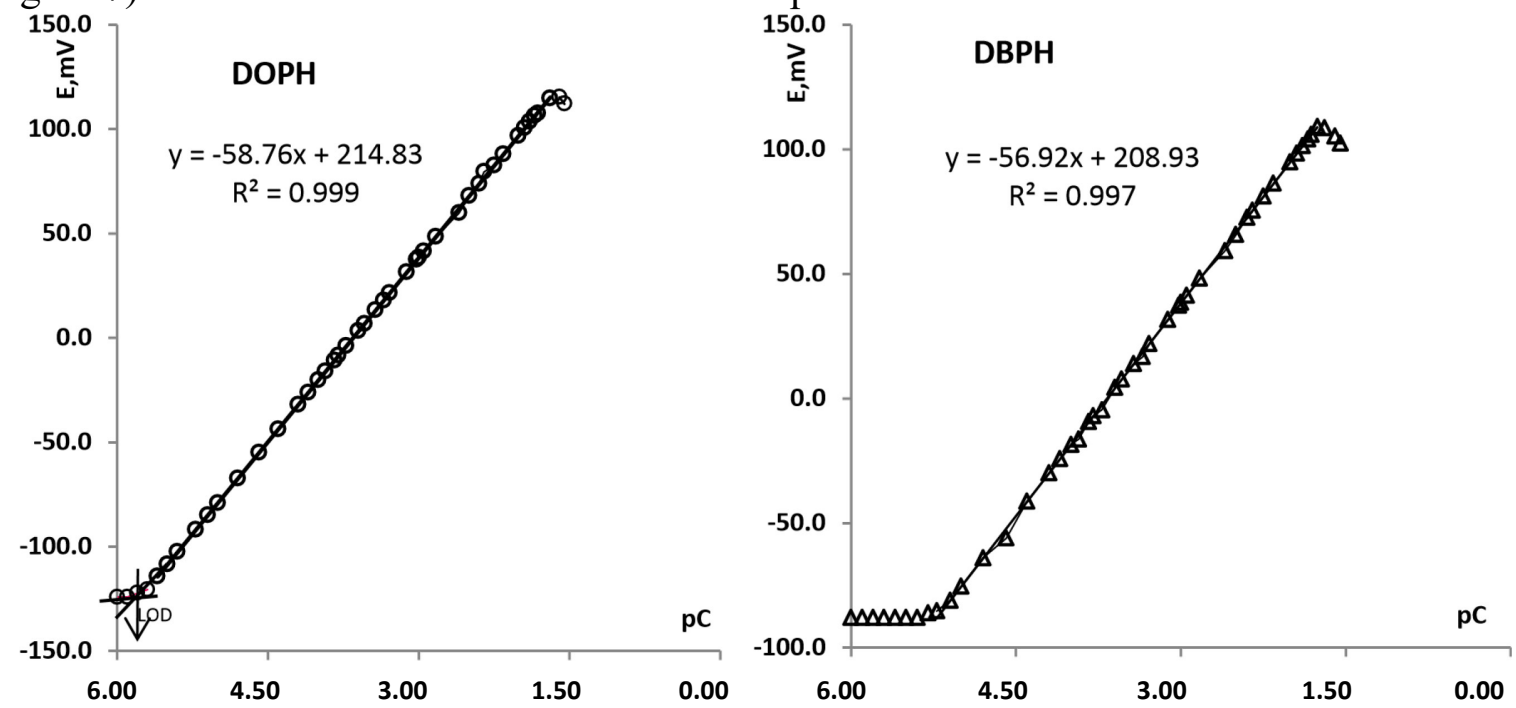

Figure 6. Calibration graph of VALD membrane electrode 


\subsection{Lifetime}

The electrode lifetime was investigated by making calibration curves and periodically testing a standard solution of $2.0 \times 10^{-6} \mathrm{M}$ to $2.0 \times 10^{-2} \mathrm{M}$ of VALD, and calculating to response slope Electrode A was found to have an operative life of more than 61 days, with the slope ranging from 58.76 to $60.58 \mathrm{mV}$.decade ${ }^{-1}$ and a linear concentration rang from $2.5 \times 10^{-6}$ to $2.0 \times 10^{-2} \mathrm{M}$. Electrode B exhibited good stability in terms of slopes of 56.92 to $51.2 \mathrm{mV}^{-d e c a d e^{-1}}$ in the linear domain of concentration from $6.0 \times 10^{-6}$ to $17.9 \times 10^{-3} \mathrm{M}$. This electrode can be used continuously for about 47 days. Two changes were observed. Firstly, a slight gradual decrease in the slope (from 56.92 to $51.20 \mathrm{mV}$.decade-1) was found, and secondly an increase in the detection limit (from $3.16 \times 10^{-6}$ to $5.8 \times 10^{-6} \mathrm{M}$ ) was noted. However, the electrodes with DOP as plasticizers could be used for about 61 days without any considerable decrease in the slope value.

Table 3. Response characteristics of membrane electrodes

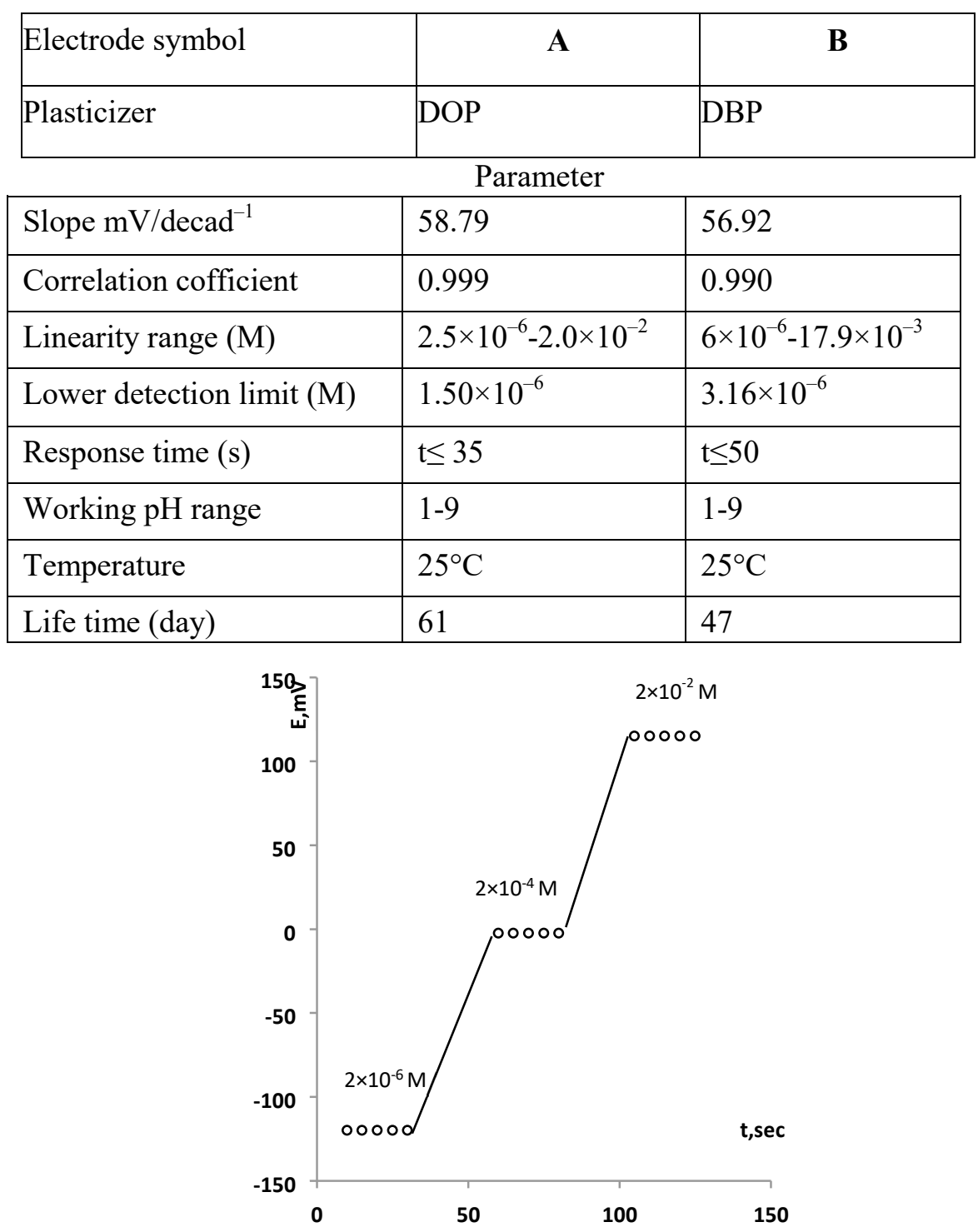

Figure.7. Plot the response time of DOP electrode using $2 \times 10^{-6} \mathrm{M}, 2.0 \times 10^{-4} \mathrm{M}$, and $2.0 \times 10^{-2} \mathrm{M}$ VALD

\subsection{Selectivity of electrode}

The influence of some inorganic cations such as of $\mathrm{Li}^{+}, \mathrm{Na}^{+}, \mathrm{K}^{+}, \mathrm{NH}_{4}^{+}, \mathrm{Ca}^{2+}, \mathrm{Mg}^{2+}, \mathrm{Ba}^{2+}, \mathrm{Zn}^{2+}$, $\mathrm{Mn}^{2+}, \mathrm{Ni}^{2+}, \mathrm{Co}^{2+}, \mathrm{Cu}^{2+}, \mathrm{Pb}^{2+}, \mathrm{Fe}^{3+}, \mathrm{Al}^{3+}, \mathrm{Cr}^{3+}$, sugars (glucose, fructose) and excipients on the electrode response was investigated. The selectivity of the electrode was measured by applying the 
matched potential method (MPM). According to this method, the activity of VALD was increased from $\mathrm{aA}=5 \times 10^{-6} \mathrm{M}$ (reference solution) to $\mathrm{a}^{\prime} \mathrm{A}$ in the range of $5 \times 10^{-5}$ to $5 \times 10^{-4} \mathrm{M}$, and the changes in potential $(\Delta \mathrm{E})$ corresponding to this increase were measured. Next, a solution of an interfering ion of concentration $\mathrm{aB}$ in the range of $3 \times 10^{-1}$ to $3 \times 10^{-2} \mathrm{M}$ is added to a new $5 \times 10^{-6} \mathrm{M}$ reference solution until the same potential change $(\Delta \mathrm{E})$ was recorded. The selectivity $K_{A, B}^{P M P}$ for each interferent was calculated using equation (1). The results are given in Tabl 4. Results reveal reasonable selectivity for VALD in presence of many related substances. The selectivity coefficient obtained by this method showed that there are no significant interferences from the cations, this reflects avery high selectivity of the investigated electrode towards VALD. The inorganic cations do not interfere owing to the differences in the ionic size, and consequently their mobilities and permeabilities as compared with VALD. The selectivity of the electrode towards neutral sugars was evaluated. The tolerance was considered as the concentration imparting a $1 \mathrm{mV}$ drift in the potential reading. The results indicate that glucose, fructose, lactose and starch do not interfere respectively. The experiments showed no interference with respect to VALD response for electrodes A and B.

\subsection{Validity of the proposed method}

The accuracy and precision of the proposed methods were carried out by four determinations at four different concentrations using both direct and standard addition methods. The precision and accuracy of the method expressed as percentage relative standard deviation as precision and \% of deviation of the measured concentration (recovery\%) as accuracy. The results obtained are within the acceptance range. Average recovery of (100.08100.61) and (99.75-101.00)\%, percentage relative standard deviation $\left(\mathrm{RSD}_{0}\right)(2.70-0.61)$ and $(2.39-0.56) \%$ respectively for electrodes $\mathrm{A}$ and B. Table 5. shows the values (RSD\%), (R\%) for different concentrations of the VALD determined from the calibration curves and by using standard addition methods (by A and B electrode). The accuracy and precision show that the electrode A has a good repeatability and reproducibility. The proposed electrodes were found to be selective for the estimation of VALD in the presence of various tablet excipients. For this purpose, a powder blend using typical tablet excipients was prepared along with the drug and then analyzed. The recoveries were not affected by the excipients and the excipients blend did not show any interference in the range of analysis correction was used. The results in Table 5. showed that the electrode based on DOP as a plasticizer was the best electrode in analysis of the tablets of VALD, since electrode has RSD (2.39-0.59) for a concentration of $\left(5.00 \times 10^{-6}-15.00 \times 10^{-3} \mathrm{M}\right)$ indicating that it has better precision than electrode $\mathrm{B}$. $\mathrm{RSD}(2.700 .61)$. Electrode based on DOP as a plasticizer were the best electrodes in analyses of the tablets.

Table 4. Selectivity coefficients for of the VALD-DTUH responsive electrode.

\begin{tabular}{|l|c|l|c|}
\hline \multicolumn{1}{|c|}{ Foreign } & \multicolumn{1}{|c|}{ KмPMA,B } & Foreign & КмРMA, \\
\hline Glucose Fructose lactose & $9.9 \times 10^{-5}$ & $\mathrm{Li}^{+}$ & $2.3 \times 10^{-3}$ \\
starch & $8.4 \times 10^{-5}$ & $\mathrm{Na}^{+}$ & $3.3 \times 10^{-3}$ \\
Micro crystalline cellulose & $7.9 \times 10^{-5}$ & $\mathrm{~K}^{+}$ & $2.0 \times 10^{-3}$ \\
Carboxy methyl cellulose & $4.3 \times 10^{-5}$ & $\mathrm{NH}_{4+}$ & $1.6 \times 10^{-3}$ \\
polyethylene glycol titanium & $8.0 \times 10^{-4}$ & $\mathrm{Mg}^{2+}$ & $6.0 \times 10^{-4}$ \\
dioxide polysorbate 80 & $1.2 \times 10^{-5}$ & $\mathrm{Ca}^{2+}$ & $9.4 \times 10^{-4}$ \\
& $6.2 \times 10^{-6}$ & $\mathrm{Ba}^{2+}$ & $5.6 \times 10^{-4}$ \\
& $4.8 \times 10^{-5}$ & $\mathrm{Zn}^{2+}$ & $7.8 \times 10^{-4}$ \\
& & $\mathrm{Mn}^{2+}$ & $7.8 \times 10^{-4}$ \\
& & $\mathrm{Ni}^{2+}$ & $7.6 \times 10^{-4}$ \\
& & $\mathrm{Co}^{2+}$ & $5.2 \times 10^{-5}$ \\
& & $\mathrm{Cu}^{2+}$ & $9.0 \times 10^{-5}$ \\
& & $\mathrm{~Pb}^{2+}$ & $4.4 \times 10^{-4}$ \\
& & $\mathrm{Cd}^{2+}$ & $5.1 \times 10^{-4}$ \\
& & $\mathrm{Fe}^{3+}$ & $8.0 \times 10$ \\
& & $\mathrm{Al}^{3+}$ & $3.3 \times 10^{-5}$ \\
& & $\mathrm{Cr}^{3+}$ & $6.6 \times 10^{-4}$ \\
\hline
\end{tabular}




\section{Analytical application}

The VALD membrane electrodes were used for the determination of VALD in pharmaceutical preparations using both direct and standard-addition methods. The direct method is the simplest for obtaining quantitative results. A calibration graph was constructed and concentration of the unknown was calculated from the linear equation of the calibration curve. Direct determinations of VALD in tablets were carried out using the developed membrane electrode (A). The results are summarized in Table 6. The content of drug in its formulation had good agreement with the declared amount. The standard addition method was applied by adding a small portion $(1 \mathrm{~mL})$ of a $0.01 \mathrm{M}$ standard VALD solution to $15 \mathrm{~mL}$ of various formulation drug concentrations $\left(2.5 \times 10^{-6}\right.$ to $\left.2.0 \times 10^{-2}\right) \mathrm{M}$. The change in the potential reading (at a constant temperature of $25^{\circ} \mathrm{C}$ ) was recorded after each addition, and was used to calculate the concentration of VALD by the equation (2). Thus, the determination of the concentration depends mainly on $\Delta \mathrm{E}$; hence, to obtain a noticeable $\Delta \mathrm{E}$, are needs to prepare a higher concentration of the standard. Results of the standard addition method are given in Table 6.

Table 5. Accuracy and precision for the determination of VALD using the proposed PVC membrane sensors in pure solution

\begin{tabular}{|c|c|c|c|c|c|c|c|c|c|}
\hline \multirow{3}{*}{ Electrode } & \multirow{3}{*}{$\begin{array}{c}\text { Taken } \\
\text { M }\end{array}$} & \multicolumn{4}{|c|}{ Direct method } & \multicolumn{4}{|c|}{ Standard-addition method } \\
\hline & & Found & $\mathrm{SD}$ & RSD & $\mathrm{R}$ & Found & SD & RSD & $\mathrm{R}$ \\
\hline & & M & M & $\%$ & $\%$ & M & M & $\%$ & $\%$ \\
\hline \multirow[t]{5}{*}{ A } & $5.00 \times 10^{-6}$ & $5.03 \times 10^{-6}$ & $9.95 \times 10^{-8}$ & 1.97 & 100.61 & $5.01 \times 10^{-6}$ & $1.20 \times 10^{-7}$ & 2.39 & 100.20 \\
\hline & $5.00 \times 10^{-5}$ & $5.02 \times 10^{-5}$ & $8.87 \times 10^{-7}$ & 1.76 & 100.41 & $5.04 \times 10^{-5}$ & $7.07 \times 10^{-7}$ & 1.40 & 100.80 \\
\hline & $5.00 \times 10^{-4}$ & $5.01 \times 10^{-4}$ & $5.63 \times 10^{-6}$ & 1.12 & 100.25 & $5.03 \times 10^{-4}$ & $5.36 \times 10^{-6}$ & 1.06 & 100.69 \\
\hline & $10.00 \times 10^{-3}$ & $10.03 \times 10^{-3}$ & $9.03 \times 10^{-5}$ & 0.90 & 100.39 & $10.04 \times 10^{-3}$ & $6.29 \times 10^{-5}$ & 0.62 & 100.46 \\
\hline & $15.00 \times 10^{-3}$ & $15.02 \times 10^{-3}$ & $1.17 \times 10^{-4}$ & 0.78 & 100.13 & $15.06 \times 10^{-3}$ & $8.48 \times 10^{-5}$ & 0.56 & 100.40 \\
\hline \multirow{5}{*}{ B } & $8.00 \times 10^{-6}$ & $8.02 \times 10^{-6}$ & $2.17 \times 10^{-7}$ & 2.70 & 100.25 & $8.05 \times 10^{-6}$ & $1.85 \times 10^{-7}$ & 2.29 & 100.62 \\
\hline & $8.00 \times 10^{-5}$ & $8.03 \times 10^{-5}$ & $1.83 \times 10^{-6}$ & 2.27 & 100.37 & $7.98 \times 10^{-5}$ & $9.58 \times 10^{-7}$ & 1.20 & 99.75 \\
\hline & $4.00 \times 10^{-3}$ & $4.02 \times 10^{-3}$ & $4.25 \times 10^{-5}$ & 1.05 & 100.55 & $4.04 \times 10^{-3}$ & $3.49 \times 10^{-5}$ & 0.86 & 101.00 \\
\hline & $8.00 \times 10^{-3}$ & $8.04 \times 10^{-3}$ & $5.63 \times 10^{-5}$ & 0.70 & 100.58 & $8.03 \times 10^{-3}$ & $6.64 \times 10^{-5}$ & 0.82 & 100.37 \\
\hline & $12.00 \times 10^{-3}$ & $12.01 \times 10^{-3}$ & $7.40 \times 10^{-5}$ & 0.61 & 100.08 & $12.06 \times 10^{-3}$ & $7.40 \times 10^{-5}$ & 0.61 & 100.50 \\
\hline
\end{tabular}

Average of four determinations

The determination of VALD in tablet was carried out using the proposed sensor. The results were compared to those obtained using the spectrophotometric method [25]. The determination of VALD in its pharmaceutical formulations Coxytow gave an average recovery of (100.29-100.84) Mean values were obtained with a Student's t- and F-tests at $95 \%$ confidence limits for four degrees of freedom, as shown in Table 6 . The data reveal that results compare favorably with those obtained by spectrophotometric. The results showed comparable accuracy (t-test) and precision (F-test), since the calculated values of $\mathrm{t}$ - and Ftests were less than the theoretical data. Value indicating no significant difference was found between the two methods. 
Table 6. Determination of VALD in its pharmaceutical preparation using the proposed sensor

\begin{tabular}{|c|c|c|c|c|}
\hline \multirow[t]{2}{*}{ Sample } & \multirow{2}{*}{$\begin{array}{l}\text { Nominal value } \\
\text { mgVALD/tablet }\end{array}$} & \multicolumn{2}{|c|}{ Potentiometry } & \multirow[t]{2}{*}{ Spectrophotometry } \\
\hline & & Direct & Standard addition & \\
\hline Coxytow & 20 & & & $100.94 \pm 1.04$ \\
\hline $\mathrm{R} \% \pm \mathrm{SD}^{\mathrm{a}}$ & & $100.96 \pm 1.83$ & $100.51 \pm 1.10$ & 2.01 \\
\hline$t$-Value ${ }^{\mathrm{b}}$ & & 1.17 & 1.04 & \\
\hline$F$-Value ${ }^{\text {b }}$ & & 3.09 & 1.11 & \\
\hline Coxytow & 10 & $100.62 \pm 1.06$ & $100.77 \pm 1.23$ & $100.64 \pm 1.21$ \\
\hline $\mathrm{R} \pm \mathrm{SD}$ & & 1.32 & 1.40 & 1.18 \\
\hline$t$-Value & & 1.30 & 1.03 & \\
\hline$F$-Value & & $100.96 \pm 1.83$ & $100.51 \pm 1.10$ & \\
\hline
\end{tabular}

a Five independent analyses .

$\mathrm{b} \quad$ Theoretical values for $\mathrm{t}-$ and $\mathrm{F}$-values at four degree of freedom and $95 \%$ confidence limit are $(\mathrm{t}=2$. 776) and $(\mathrm{F}=6.26$.

\section{CONCLUSION}

VALD selective electrodes based on ion pair complex of VALD-DTUH and with different plasticizers were constructed. The best VALD electrode was based on DOP. This electrode was used for drug determination in pharmaceutical preparations. The electrode based on DOP gave excellent electrode parameters and no interference with several cations.. The presented methods for the determination of VALD with the prescribed electrodes are simple, sensitive, highly specific and advantageous over the previously described procedures for VALD determination

\section{Acknowledgement}

The author express their thanks to Dr, Mohammed Samer Bassmajei, Department of Chemistry, Aleppo University, Faculty of Sciences, for providing all the assistance during the work.

\section{References}

[1] Talley J.J, Brown D.L, Carter J.S, Graneto M.J, Koboldt C.M, Masferrer J.L, Perkins W.E, Rogers R.S, Shaffer A.F, Zhang Y.Y, Zweifel B.S, Seibert K., J Med Chem. 43(2000) 775.

[2] Gotta A W., Curr Opin Invest Drugs. 3(2002) 240.

[3] Makarowski W, Zhao W W, Bevirt T, Recker D P., Osteo-arthr Cartil. 10 (2002) 290.

[4] Fricke J, Varkalis J, Zwillich S, Adler R, Forester E., Recker D P, Verburg K M., Am J Ther. 9 (2002) 89.

[5] Kivitz A, Eisen G, Zhao W W, Bevirt T., Recker D P., J Fam Pract. 51 (2002) 530.

[6] Daniels S E, Talwalker S, Torri S, Snabes M C, Recker D P, Verburg K M., Obstet Gynecol. 100 (2002) 350.

[7] Yang J J, Zhang D C, Bible B, Karim A, Findlay J A W., Drug Metab Dispos. 30 (2002) 1013.

[8] Karim A, Laurent A, Slater M E, Kuss M E, Qian J, Crosby-Sessoms S L., Hubbard R C.,. J Clin Pharmacol. 41 (2001) 1111.

[9] Ibrahim A, Park S, Feldman J, Karim A, Kharasch E D., Anesthesiol-ogy. 96 (2002) 88.

[10] Sivasubramanian L, Devarajan L., Internat J Chem Tech Res. 1 (2009) 96. 
[11] Gandhimathi M, Ravi T K, Shukla N, Sowmiya G., Indian J Pharm Sci. 69 (2007) 145. [12] Ravi T K, Gandhimathi M, Suganthi A, Sarovar S., J Separation Sci. 29 (2006) 1647.

[13] Sérgio L D, Marcio F, Nogueira R D, Bizogne S R, Bernardi R M., J liquid chromatogr related technol. 30 (2007) 17.

[14] Keshetty S, Venisetty R K, Molmoori V, Ciddi V., Die Pharmazie. 61 (2006) 242.

[15] Subramanian G, Faisal M B V, Ranjith Kumar A, Udupa N., Indian J Pharm Sci. 68 (2006) 391.

[16] Zecevic M, Savic G, Zivanovic L., Anal. Lett. 39 (2006) 1875.

[17 Pavan Kumar V V, Vinu M C, Ramani A V, Mullangi R, Srinivas N R., Biomed. Chromatogr. 20 (2006) 125.

[18] Ramaa C S, Deshpande D K, Shirode A R, Wamorkar V V, Kakad A B, Kadam. V J., Indian J Pharm Sci. 68 (2006) 514.

[19] Werner U, Werner D, Hinz B, Lambrecht C, Brune K., Biomed. Chromatogr. 19 (2005) 113.

[20] Suganthi A, Sivakumar H B, Shrikumar S, Gandhimathi M, Gopal R M, Ravi T K., Indian J Pharm Sci. 67 (2005) 757.

[21] Ramakrishna N V S, Vishwottam K N, Wishu S, Koteshwara M. J Chromatogr B Anal Technol Biomed Life Sci. 802 (2004) 271.

[22] Sankar A S K, Anandakumar K, Nagavalli D, Senthil P M, Vetrichelvan T, Nithyanandham. K., Indian J Pharm. Sci. 69 (2007) 132.

[23] Sane R T, Menon S, Deshpande A Y, Jain A., Chromatographia. 61 (2005) 137.

[24] Suganthi A, Sivakumar H B, Vijayakumar S C, Ravimathi P, Ravi T K., Indian J Pharm. Sci. 68 (2006) 373.

[25] Devarajan L, Sivasubramanian L., Indian J Pharm Sci. 68 (2006) 240.

[26] Aditya. N, Arora R K, Tiwari M., Indian J Pharm Sci. 68 (2006) 370.

[27] Nagulwar V, Tajne M R, Upadhaye K, Bakhle S, Deshpande S, Wadetwar R., Indian J Pharm Sci. 67 (2005) 624.

[28] Sutariya V B, Mashru R, Sankalia M G., Parikh P., Indian J Pharm. Sci. 66(2004), 360-

[29] Goudaa A A, El-Sayedb M I K, Aminc A S, El Sheikh R., Arabian Journal of Chemistry.6 (2013) 145.

[30] Craggs A, Moody G J, Thomas J D R., J Chem Edu. 51 (1974) 541.

[31] Umezawa Y, Hlmann Ph B, Umezawa K, Tohda K, Amemiya Sh., Pure ApplChem. 72 (2000) 1851.

[32] Umezawa Y, Umezawa K, Sato H., Pure Appl Chem. 67 (1995) 507.

[33] Peter G, Hayes J M, Hieftje G M., Saunders, Philadelphia, USA. (1974).

[34] Baumann E., Anal Chim Acta. 42 (1968) 127.

[35] Issa Y M, Hassouna M M, Abdel-Gawad F M, Hussien E M., J Pharm Biomed Anal. 23 (2000) 493. 